\title{
Use of new cannulated screws for primary sternal closure in high risk patients for sternal dehiscence
}

\author{
Giuseppe De Cicco ${ }^{1}$, Davide Tosi ${ }^{2}$, Roberto Crisci $^{3}$, Andrea Bortolami ${ }^{4}$, Tommaso Maria Aquino ${ }^{1}$, \\ Aldo Prencipe ${ }^{1}$, Gerardo Di Matteo ${ }^{1}$, Stefano Benussi ${ }^{1}$
}

${ }^{1}$ Unit of Cardiac Surgery, Spedali Civili di Brescia, Brescia, Italy; ${ }^{2}$ Unit of Thoracic Surgery and Lung Transplantation, Fondazione IRCCS Ca' Granda-Ospedale Maggiore Policlinico di Milano, Milano, Italy; ${ }^{3}$ Thoracic Surgery Unit, University of L'Aquila, “G. Mazzini” Hospital, Teramo, Italy; ${ }^{4}$ Unit of Cardiac Surgery, Ca' Foncello, Treviso, Italy

Contributions: (I) Conception and design: G De Cicco, D Tosi; (II) Administrative support: A Bortolami, S Benussi, G De Cicco, R Crisci; (III) Provision of study materials or patients: TM Aquino; (IV) Collection and assembly of data: A Prencipe, A Bortolami, G De Cicco; (V) Data analysis and interpretation: G Di Matteo, G De Cicco, A Bortolami; (VI) Manuscript writing: All authors; (VI) Final approval of manuscript writing: All authors.

Correspondence to: Davide Tosi, MD. Unit of Thoracic Surgery and Lung Transplantation, Fondazione IRCCS Ca' Granda-Ospedale Maggiore Policlinico, via F. Sforza, 35, 20122, Milan, Italy. Email: davide.tosi@policlinico.mi.it.

Background: Median sternotomy is still the approach of choice for heart surgery and the most common sternal closure is conventional six-wire technique. Mediastinitis is the frightening complication of the median sternotomy and occurs from $1 \%$ up to $2.4 \%$ of cases with a mortality rate which ranges from $14 \%$ up to $47 \%$. Many methods have been suggested to reinforce the sternum with the common goal to improve sternal stability and prevent mediastinitis, but there is not consensus among cardiac surgeons on the optimal way to close the sternum. For this reason, we report our experience with a sternal device that, although not entirely new as a concept, has new technical features and plays a new role in preventing sternal dehiscence, according to the most recent findings on mechanism which leads to sternal dehiscence.

Methods: We enrolled 62 high risk patients for sternal dehiscence (patients with 2 well established historical risk factors), and we closed the sternum of the patients with a new surgical option consisting of passing, in a conventional six-wire sternal closure, the last sixth steel wire $\left(\varnothing 1.0 \mathrm{~mm}, \mathrm{n}^{\circ} 5\right)$ through a couple of titanium cannulated screws (Ø $5.5 \mathrm{~mm}$, self-tap-ping with a length from 10 to $16 \mathrm{~mm}$ and $2-\mathrm{mm}$ increments) inserted into the 5 th or 6 th couple of rib cartilages.

Results: Primary chest closure with cannulated screws was performed on 48 males and 14 females. The average age of patients was 67.6 years (range, $43-88$ years). The average follow-up was $12.8 \pm 16.2$ months (range, 1-41 months). Chronic obstructive pulmonary disease (COPD) was the most common preoperative risk factor. The average number of risk factors was 2.4 (range, 2-4). Coronary artery bypass grafting (CABG) was the most common cardiac procedure. There were no peri-operative deaths. $\mathrm{BMI}>30 \mathrm{Kg} / \mathrm{m}^{2}$ and diabetes were the associated of risk factors predisposing to superficial skin dehiscence.

Conclusions: In our clinical experience with high risk patients, this surgical option suggests that there is evidence of an effective stabilization of standard sternal closure and this option seems a promising technique to prevent the domino effect which starts from the xifoid bone and proceeds to the manubrium with the effect of leading to sternal instability which is the first step to mediastinitis.

Keywords: Mediastinitis; sternal dehiscence; sternal closure

Submitted Jun 19, 2019. Accepted for publication Oct 10, 2019.

doi: $10.21037 /$ jtd.2019.10.79

View this article at: http://dx.doi.org/10.21037/jtd.2019.10.79

(C) Journal of Thoracic Disease. All rights reserved. 


\section{Introduction}

Median sternotomy is still the approach of choice for heart surgery and the most common sternal closure is conventional six-wire technique. The median sternotomy exposures patients to infections which can lead to mediastinitis which occurs from $1 \%$ up to $2.4 \%$ of cases with a mortality rate which ranges from $14 \%$ up to $47 \%$ $(1,2)$. For this reason, many methods have been suggested to reinforce the sternum with the purpose of preventing mediastinitis. These methods range from different prophylactic therapy measures to various techniques of sternal closures. Common goal of the sternal closures is improvement of sternal stability, so that osteosynthesis is promptly promoted avoiding, in this way, mediastinitis. Nevertheless, there is not consensus among cardiac surgeons on the optimal way to close the sternum because all the ways suggested present some disadvantages: (I) sternal closure techniques based on different ways of sternal wire fixation are often unwieldy procedures which are adding to the blood losses; (II) sternal plate fixation leads to an extension of the sternal closure time and a loss of precious time in case of emergent chest re-entry surgery. Moreover, patients with sternal plate fixation experience some discomfort because of extensive use of hardware; (III) sternal closure with devises inserted into the intercostal spaces need a symmetrical sternotomy so that the devices are properly inserted, and their fixing forces are symmetrical distributed. Therefore, we report our experience with a sternal device that, although not entirely new as a concept, has new technical features and plays a new role in preventing sternal dehiscence, according to the most recent findings on mechanism of sternal dehiscence (3).

\section{Methods}

From January 2014 to December 2017 we enrolled 62 high risk patients. Patient pre-operative characteristics are shown in the Table 1. High risk patient for sternal dehiscence was defined as patient having 2 or more the following established acknowledged risk factors: chronic obstructive pulmonary disease (COPD), re-operative surgery, Renal failure (creatinine $>1.5 \mathrm{mg} / \mathrm{dL}$ ), diabetes, chronic steroid use, obesity (BMI $>30 \mathrm{Kg} / \mathrm{m}^{2}$ ), off-midline sternotomy,
Table 1 Preoperative and intraoperative data

\begin{tabular}{|c|c|}
\hline Characteristics & \\
\hline Age & $67.6 \pm 10.3$ \\
\hline \multicolumn{2}{|l|}{ Gender } \\
\hline Male & 48 \\
\hline Female & 14 \\
\hline Euro score (log. 2) & $1.8 \pm 0.46$ \\
\hline \multicolumn{2}{|l|}{ Preoperative $(\mathrm{N}=62)$} \\
\hline \multicolumn{2}{|c|}{ Combination risk factors (inclusion criteria) } \\
\hline Obesity + COPD & 18 \\
\hline Obesity + diabetes & 12 \\
\hline Diabetes + renal failure & 9 \\
\hline COPD + long CPB & 5 \\
\hline Off-midline sternotomy + diabetes & 4 \\
\hline Diabetes + long CPB & 3 \\
\hline Diabetes + chronic steroid use & 2 \\
\hline Long CPB + chronic steroid use & 2 \\
\hline Long CPB + renal failure & 2 \\
\hline Diabetes + transverse fractures & 2 \\
\hline Diabetes + sternal osteoporosis & 1 \\
\hline Diabetes + paraplegia & 1 \\
\hline Diabetes + psychosis & 1 \\
\hline \multicolumn{2}{|l|}{ Intraoperative (N=62) } \\
\hline CABG & 51 \\
\hline On Pump & 45 \\
\hline Off pump & 11 \\
\hline Double mammary & 7 \\
\hline $\mathrm{AVR}+\mathrm{CABG}$ & 4 \\
\hline MVR & 2 \\
\hline AVR & 2 \\
\hline Acute aortic dissection & 2 \\
\hline TVR & 1 \\
\hline \multicolumn{2}{|c|}{$\begin{array}{l}\text { COPD, chronic obstructive pulmonary disease; CPB, } \\
\text { cardiopulmonary bypass; CABG, coronary artery bypass } \\
\text { grafting; AVR, aortic valve replacement; MVR, mitral valve } \\
\text { replacement; TVR, tricuspid valve replacement. }\end{array}$} \\
\hline
\end{tabular}




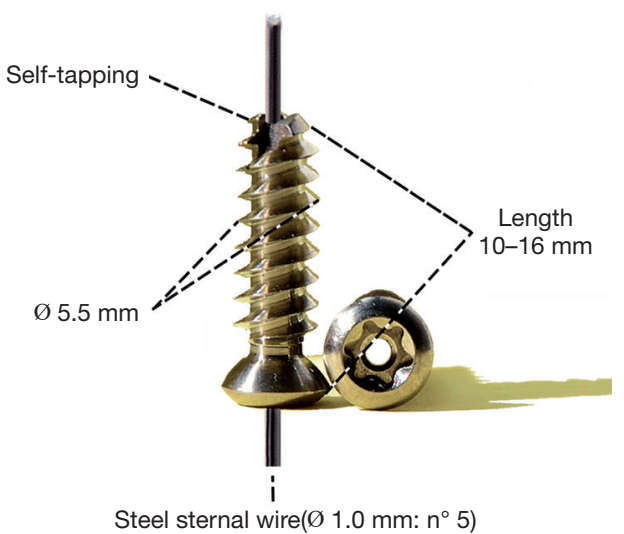

Figure 1 Features of the SCS-thorax screws.

osteoporosis, long cardio-pulmonary bypass runs $(>2 \mathrm{~h})$, transverse fractures of the sternum (4). In our experience as risk factors we added uncooperative patients (psychotic patients and mental insufficiency patients) and patients using crutches and/or wheelchair (patients affected by paraplegia, polio, etc.).

\section{Surgical technique}

The surgical technique consisted of reinforcing a conventional six-sternal-wire closure with a couple of titanium screws (SCS-Thorax, PSM Medical Solutions, Tuttlingen, Germany) (Figure 1). The titanium sternal screws display the following characteristics:

(I) cannulated titanium sternal screws (Ø $5.5 \mathrm{~mm})$, self-tapping with a length from 10 to $16 \mathrm{~mm}(2-\mathrm{mm}$ increments); (II) steel sternal wire (Ø $\left.1.0 \mathrm{~mm}, \mathrm{n}^{\circ} 5\right)$ with a length $750 \mathrm{~mm}$.

The sternal closure technique used is synoptically depicted in the Figure 2. All patients received a sternal closure with five steel wires and a couple of cannulated screws. Two steel wires were passed through the bone of the manubrium, three steel wires were passed through the intercostal spaces, encircling the sternal body. Then the 5th or 6th couple of the false rib cartilages were exposed and entirely drilled near the chondrosternal joints (Figure 2A). These points have a wider area for housing the screws and thus avoid the problem related to a mismatch between the diameter of the screw and the width of the chondral cartilage. This problem could lead to cartilage fracture with screw avulsion and failure of the reinforcement system. With a calliper inserted into the hole the thickness of the rib cartilage was measured (Figure 2B). This direct measurement dictated the length of the cannulated screws.
After tightening the screws (Figure 2D), an $\mathrm{n}^{\circ} 5$ steel wire was passed through the screws. The chest was closed, and all the steel wires were twisted (Figure 2C). Since excess wire twisting does not increase closure strength, wire twisting was optimized to three twists (5). The screw-wire was cut and completely twisted first. Only after that the same was done with the other steel wires. In this way, in case of rupture of the screw-wire, a new wire can be passed through the screws only de-twisting the other steel wires without need to pass all steel wires twice. Finally, the skin was closed with a triplelayer suture. Patients were followed up clinically by the cardiac surgical team. Successful sternal closure was defined by physical exam as a wound with lack of instability, pain and healing complications. Moreover, to define a successful sternal closure, radiographs had to show an image with an unchanged location of screws for a minimum of 4 weeks (Figure 2D). Sternal closure was performed by the same cardiac surgeon at the end of the cardiac procedure.

\section{Results}

Primary chest closure with cannulated screw was performed on 48 males and 14 females. The average age of patients was 67.6 years (range, 43-88 years). The average follow-up was $12.8 \pm 16.2$ months (range, $1-41$ months). COPD was the most common pre-operative risk factor. The average number of risk factors was 2.4 (range, 2-4). Coronary artery bypass grafting $(\mathrm{CABG})$ was the most common cardiac procedure. There were no peri-operative deaths. Two patients developed a superficial skin dehiscence, but in no case sternal dehiscence occurred. This happened in two patients who underwent $\mathrm{CABG}$ whit $\mathrm{BMI}>30 \mathrm{Kg} / \mathrm{m}^{2}$ and diabetes. As already mentioned, the time taken to insert the cannulated screws scarcely added ten extra minutes to the time for a conventional six-wire sternal closure. There were no intraoperative complications apparently related to implantation of the screws.

\section{Discussion}

Instability of sternal closure after median sternotomy has been demonstrated to compromise sternal wound integrity leading to complications which range from prolonged incisional pain to dehiscence/mediastinitis $(6,7)$. Therefore, an effective primary sternal closure is needed to prevent sternal dehiscence, particularly in patients with high risks. In this regard a number of published papers have suggested technical modifications of sternal wiring (in terms of wiring 

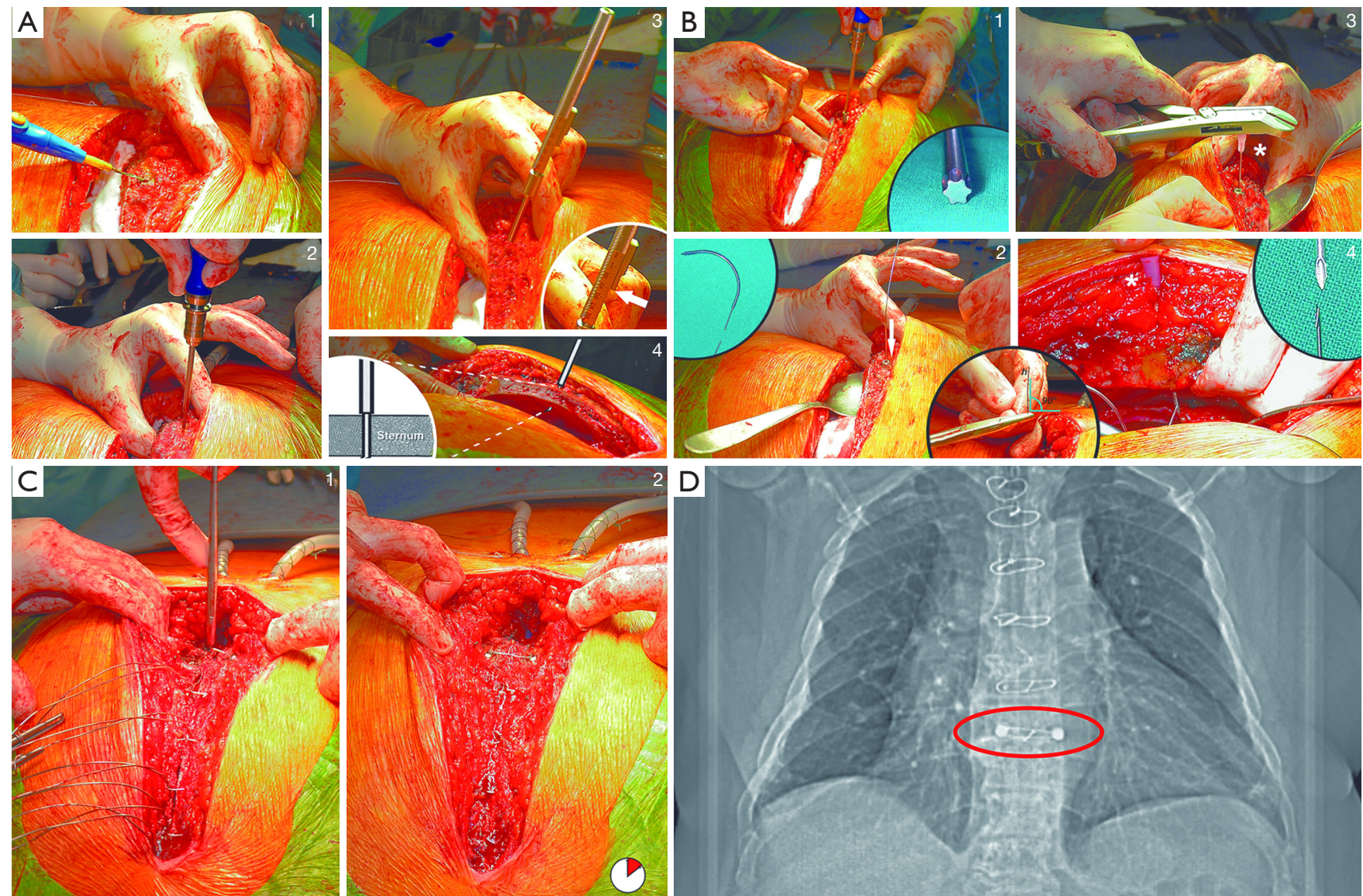

Figure 2 Main steps of the surgical technique. (A) 1: exposition of the last couple of the false ribs; 2: drilling of the last couple of the false ribs near the chondro-sternal joints; 3: insertion of a calliper into the hole (a) and measure of the thickness of the rib (4); (B) 1: screwing of a couple of $\mathrm{n}^{\circ} 14$ cannulated screws (window: torx tip of the screwdriver); 2: passing (out-in) of a $\mathrm{n}^{\circ} 5$ steel wire (after cutting the needle as shown in the window) through the hole of the first cannulated screw; 3,4: use of a G21 needle $\left(^{*}\right)$ facilitating the passing (in-out) of the steel wire through the second screw (after sharp cutting of the wire for a better fitting into the needle hole); (C) 1: twisting of the steel wires starting from the screwwire; 2: result after cut of all steel wires; (D) chest X ray of the patient on 4th post-operative day with the screws $i n$ situ red circled.

configuration, number of sternal fixation points, number of steel wire for each point, number of twists) with the common goal to stabilise better the sternal bone (1,8-14). Other studies with the same aim have suggested the use of various materials (such as mersilene ribbon, nylon bands, steel or polyether- ether-ketone bands, absorbable radiopaque pins, thermo-reactive clips, sliding titanium clips, stainless steel coils, stainless steel plates, titanium plates) (15-23). However, all these suggested surgical options failed to influence clinical practice, therefore there is no consensus among surgeons on the optimal method for sternal closure. Presumably, for that reason, steel wiring is still the standard technique for sternal closure, although stable sternal fixation remains one of the prerequisites for a good bone healing. Therefore, we were focused on the biomechanical studies of the closed sternum after median sternotomy with the aim to find a technique that does not deviate too far from the standard six-wire sternal closure and, on the other hand, promotes a speedy sternal healing through a stabilization of the sternal sites showing the greater mobility (24-27). These biomechanical studies have tested the stability of the three different parts of the closed sternum: manubrium, body and xifoid bone. Although the tests have been performed using inhomogeneous materials and different closure techniques, all the studies have confirmed that the most mobile sites of the sternotomy are the xifoid bone and the lower end of the sternal body. For this reason, Dasika and associates have suggested 
reinforcing these sites with additional steel wires (26). Moreover, in a conventional six-wire sternal closure, Shin and associates hypothesized that use of two/four extra steel wires, almost always passed close to the sternoxiphoid junction, could explain why in their experience the lower part of the sternum has showed the better healing in comparison to the other sternal parts (28). Nevertheless, before Casha's studies, no authors had elucidated the mechanism leading to sternal dehiscence 3. Casha and associates, by using finite element analysis (FEA), have studied the forces acting on the sternum during coughing at different rib levels and the mechanism of sternotomy dehiscence of a conventional sixwire-sternal closure (3). Data have showed that threshold necessary for a conventional six-wire sternal closure to dehisce by pivoting at the upper part of the sternum was 84 Newton meters $(\mathrm{N} \cdot \mathrm{m})$, whereas a 40 kilopascal $(\mathrm{kPa})$ cough produces a $92 \mathrm{~N}$ m rotational moment. By comparing these two measurements, Casha and associates have suggested that dehiscence process of a conventional six-wire sternal closure occurs starting from the xiphoid bone and proceeds cranially, like a domino effect. Casha and associates have deduced, as well, the causes of this process. Firstly, this occurs because of the circumferential forces which distract the chest, and these are greater at the lower end of the sternum according to the FEA model which predicts that the chest wall tension is proportional to the tangential radius at the relative chest level. Secondly, there is a concentration of forces in the lower part of the sternum because here the 5 th, 6 th and 7 th ribs converge attaching roughly to the same sternum site. Thirdly, the 7th rib carries additional forces conferred on it by the 8th, 9th and 10th which attached on its inferior coastal margin. These three mechanisms contribute to determining that sternum dehiscence mostly starts from the inferior part of the sternotomy wound. For all these reasons, also Casha and associates have suggested that adding one extra sternal wire at the lower end of the sternotomy the rotational moments necessary to dehisce the conventional wired sternal closure increase to 107 $\mathrm{N} \cdot \mathrm{m}$, while the addition of an eighth sternal wire in the same site would increase the moments to $127 \mathrm{~N} \cdot \mathrm{m}$ (3). In other words, according to the Casha's FEA model, a conventional six-sternal-wire closure is insufficient to resist to the forces generated by a loud cough, therefore these forces lead to sternal dehiscence which has its trigger point in the lower end of the sternotomy (3). Starting from these findings, we have presumed that reinforcing the sixth steel wire, generally passed through the 5 th or 6 th rib cartilage, with a couple of cannulated screws would have conferred the needed sternal strength against the cutting forces put in place by a six-sternal-wire closure following a $40 \mathrm{kP}$ cough. Although this study is not a matched case-control study, our experience in high risk patients suggests that the screw reinforcement is effective in performing a better sternal closure in terms of stability and seems a promising technique to prevent the already mentioned domino effect. Moreover, the cannulated screws present the primary advantage that they are inserted into the rib cartilage/bone, so that, in case of paramedian sternotomy with rupture of the sternal bone between the ribs, the cannulated screws can be a more stable option compare to sternal wiring and an easier alternative compare to sternal plating.

In this paper the control group is missing and this is a limitation of the study. On the other hand, undergoing patients, with above mentioned risk factors for sternal dehiscence, a conventional six-sternal-wire closure is outside the policy of our centre. In fact, we recommend in these patients to always reinforce the sternal closure and the use of cannulated screws is our method in use.

\section{Conclusions}

Use of the cannulated screws is safe for the patient, effective, reproducible, inexpensive and causes no additional morbidity. Finally, in experienced hands, the time taken to insert the cannulated screws adds scarcely ten extra minutes to the time for a conventional six-wire sternal closure, because the insertion technique presents no significant variations from the standard applied technique of sternal closure.

\section{Acknowledgments}

None.

\section{Footnote}

Conflicts of Interest: The authors have no conflicts of interest to declare.

Ethical Statement: The authors are accountable for all aspects of the work in ensuring that questions related to the accuracy or integrity of any part of the work are appropriately investigated and resolved. This study is a retrospective analysis and was not registered as a clinical trial. There was no need of ethics approval. All patients had signed an informed consent form before surgery. 


\section{References}

1. Ridderstolpe L, Gill H, Granfeldt H, et al. Superficial and deep Sternal wound complications: incidence, risk factors and mortality. Eur J Cardiothorac Surg 2001;20:1168-75.

2. Gårdlund B, Bitkover CY, Vaage J. Postoperative mediastinitis in cardiac surgery: microbiology and pathogenesis. Eur J Cardiothorac Surg 2002;21:825-30.

3. Casha AR, Manché A, Gatt R, et al. Mechanism of sternotomy dehiscence. Interact Cardiovasc Thorac Surg 2014;19:617-21.

4. Zacharias A, Habib RH. Factors predisposing to median sternotomy complications: deep vs. superficial infection. Chest 1996;110:1173-8.

5. Glennie S, Shepherd DET, Jutley RS. Strength of wired sternotomy closures: effect of number of wire twists. Interact CardioVasc Thorac Surg 2003;2:3-5.

6. Bitkover CY, Gardlund B. Mediastinitis after cardiovascular operations: a case-control study of risk factors. Ann Thorac Surg 1998;65:36-40.

7. Stoney WS, Alford WC Jr, Burrus GR, et al. Median sternotomy dehiscence. Ann Thorac Surg 1978;26:421-6.

8. Cohen DJ, Griffin LV. A biomechanical comparison of three sternotomy closure techniques. Ann Thorac Surg 2002;73:563-8.

9. Bottio T, Rizzoli G, Vida V, et al. Double crisscross sternal wiring and chest wound infections: A prospective randomized study. J Thorac Cardiovasc Surg 2003;126:1352-6.

10. Totaro P, Degno N, Argano V. Longitudinal Reinforcement for Treatment of Sternal Dehiscence. Asian Cardiovasc Thorac Ann 2006;14:432-4.

11. Robicsek F, Daugherty HK, Cook JW. The prevention and treatment of sternum separation following open-heart surgery. J Thorac Cardiovasc Surg 1977;73:267-8.

12. Schimmer C, Reents W, Elert O. Primary closure of median sternotomy: a survey of all German surgical heart centers and a review of the literature concerning sternal closure techniques. Thorac Cardiovasc Surg 2006;54:408-13.

13. Kiessling AH, Isgro F, Weisse U, et al. Advanced Sternal Closure to Prevent Dehiscence in Obese Patients. Ann Thorac Surg 2005;80:1537-9.

14. Shaikhrezai K, Robertson FL, Anderson SE, et al. Does the number of wires used to close a sternotomy have an impact on deep sternal wound infection? Interact Cardiovasc Thorac Surg 2012;15:219-22.

15. LeVeen HL, Piccone VA. Nylon-band chest closure. Arch Surg 1968;96:36-9.

16. Johnston RH, Garcia-Rinaldi R, Vaughan GD, et al. Mersilene ribbon closure of the median sternotomy: an improvement over wire closure. Ann Thorac Surg 1985;39:88-9.

17. Kalush SL, Bonchek LI. Peristernal closure of median sternotomy using stainless steel bands. Ann Thorac Surg 1976;21:172-3.

18. Negri A, Manfredi J, Terrini A, et al. Prospective evaluation of a new sternal closure method with thermoreactive clips. Eur J Cardiothorac Surg 2002;22:571-5.

19. McGregor WE, Payne M, Trumble DR, et al. Improvement of Sternal Closure Stability With Reinforced Steel Wires. Ann Thorac Surg 2003;76:1631-4.

20. Grapow MT, Melly LF, Eckstein FS, et al. A new cabletie based sternal closure system: description of the device, technique of implantation and first clinical evaluation. J Cardiothorac Surg 2012;7:59.

21. Zeitani J, Penta de Peppo A, Bianco A, et al. Performance of a Novel Sternal Synthesis Device After Median and Faulty Sternotomy: Mechanical Test and Early Clinical Experience. Ann Thorac Surg 2008;85:287-93.

22. Vincent JG. Update on sternal osteosyntesis. Ann Thorac Surg 1986;41:216-8.

23. Sargent LA, Seyfer AE, Hollinger J, et al. The healing Sternum: A Comparison of Osseous Healing with Wire Verses Rigid Fixation. Ann Thorac Surg 1991;52:490-4.

24. Pai S, Gunja NJ, Dupak EL, et al. In vitro comparison of wire and plate fixation for midline sternotomies. Ann Thorac Surg 2005;80:962-8.

25. McGregor WE, Trumble DR, Magovern JA. Mechanical analysis of midline sternotomy wound closure. J Thorac Cardiovasc Surg 1999;117:1144-50.

26. Dasika UK, Trumble DR, Magovern JA. Lower sternal reinforcement improves the stability of sternal closure. Ann Thorac Surg 2003;75:1618-21.

27. Bruhin R, Stock UA, Drücker JP, et al. Numerical simulation techniques to study the structural response of the human chest following median sternotomy. Ann Thorac Surg 2005;80:623-30.

28. Shin YC, Kim SH, Kim DJ, et al. Sternal Healing after Coronary Artery Bypass Grafting Using Bilateral Internal Thoracic Arteries: Assessment by Computed Tomography Scan. Korean J Thorac Cardiovasc Surg 2015;48:33-9.

Cite this article as: De Cicco G, Tosi D, Crisci R, Bortolami A, Aquino TM, Prencipe A, Di Matteo G, Benussi S. Use of new cannulated screws for primary sternal closure in high risk patients for sternal dehiscence. J Thorac Dis 2019;11(11):45384543. doi: $10.21037 /$ jtd.2019.10.79 